\title{
Mini-Commentary on 'Would an exclusive contraceptive clinic help meet the needs of patients attending an integrated sexual health clinic?'
}

\section{Sharon Moses}

Consultant, Sexual and Reproductive Health, Bristol Sexual Health, Central Health Clinic, Bristol, UK

\section{Correspondence to}

Dr Sharon Moses, Bristol Sexual Health, Central Health Clinic, Tower Hill, Bristol BS2 OJD, UK; smoses@doctors.org.uk

Accepted 17 August 2015

\section{SLinked}

- http://dx.doi.org/10.1136/ jprhc-2015-101280

\section{CrossMark}

To cite: Moses S. J Fam Plann Reprod Health Care 2015;41:312-313.
In her Anne Szarewski Journal Memorial Award 2015 prize-winning essay, ${ }^{1}$ Dr Laura Percy eloquently outlines an unmet need in her service. She describes established users of contraception having difficulty in accessing repeat prescriptions for pills or administration of the contraceptive injection with their general practitioner (GP), and long waits in the integrated sexual health clinic for this indication. The proposed solution was to pilot a nurse-led clinic exclusively for straightforward repeat contraception.

I remember as a trainee listening to senior colleagues discuss how the National Health Service (NHS) goes through regular cycles of change and service redesign, and have now been around for long enough to see this in action. In 2001, the National Strategy for Sexual Health and $\mathrm{HIV}^{2}$ was the main trigger for the integration of genitourinary medicine (GUM) and contraception services and the provision of patient-focused holistic care. It also outlined levels of service provision and expectations of specialist GUM and contraception services.

Dr Percy has essentially described a Level 1 nurse-delivered clinic from a Level 3 service. Fantastic for patients who do not want to wait or see their GP but is it a realistic solution? GPs are expected to be the main Level 1 providers and are paid to provide Level 1 contraception in their General Medical Services contract. Certainly most commissioning groups have the expectation that specialist services should mainly deliver complex sexual health care as they do not want to pay twice for Level 1 activity.
Most contraceptive services are still funded by a block contract, and Level 1 activity could be considered poor value for money as part of a block.

Difficulties experienced by patients in Dr Percy's service included long waiting times in the integrated 'queue and wait' clinic. There are several models in use nationally for reducing waiting times in open-access services. My service, for instance, offers an integrated walk-in clinic with a time slot system to reduce patient waits. Patients can therefore routinely obtain Level 1 and 2 contraception alongside sexually transmitted infection (STI) screening and treatment and so their holistic needs are met. There is no issue if they choose to attend solely for contraception, but a separate clinic is not required and dual training of staff remains a priority.

GUM and contraception services are often better placed than GPs to pick up psychosexual and hidden or embarrassing sexual health issues. There is potential for these concerns to be missed in a very prescriptive exclusive contraception clinic where a woman may feel she cannot discuss anything else. A preferred direction might be to look at external settings and working with other health care professionals such as pharmacists and practice nurses to see if Level 1 contraception clinics could be established in alternative community settings.

An additional concern about an exclusive contraception clinic would be a decline in opportunistic testing for STIs as patients may not want to wait to see someone else for STI screening. It goes without saying that long-acting reversible 
contraceptive methods should be discussed with all attendees even if they are satisfied with their established/current method.

Finally, I would suggest that networking is essential with other local sexual health providers to raise awareness of the unmet need and apparent deficiencies in existing Level 1 services. This would include feedback to local GPs about difficulties patients are having accessing their surgeries for repeat contraception and the preference for evening clinics.

So does integration of contraception and STI testing not work for some patients? Possibly, but within the constraints of commissioning arrangements and cost savings with adequate clinical training and service design we can continue to manage patients holistically and meet all their sexual health needs.

Competing interests None declared.

Provenance and peer review Commissioned; internally peer reviewed.

\section{REFERENCES}

1 Percy LA. Would an exclusive contraceptive clinic help meet the needs of patients attending an integrated sexual health clinic? J Fam Plann Reprod Health Care 2015;41:309-11.

2 Department of Health. The National Strategy for Sexual Health and HIV. London, UK: Department of Health, 2001. 